\title{
Sleep HERMES: a European Core Syllabus in respiratory disorders during sleep
}

\author{
W. De Backer \\ A. Simonds \\ V. Horn \\ S. Andreas \\ M. Bonsignore \\ P. Calverley \\ V. Donic \\ P. Levy \\ S. Mitchell \\ W. McNicholas \\ M. Morrell \\ W. Randerath \\ R. Riha \\ H. Trang \\ J. Verbraecken \\ P. Palange
}

Within the HERMES model, a process of establishing consensus standards for training largely follows four key phases (fig. 1). In line with this developmental strategy, the Sleep HERMES Task Force will produce collective documentation and activities to support a syllabus, curriculum and European examination $[7,8]$. The Task Force proposed development of a core syllabus in RSM as well as educational diagnostics and therapeutics guidelines (RSM curriculum) based on phase 1 (the syllabus).

The HERMES Sleep Task Force and project were officially launched during the ERS Annual Congress in Vienna, September 2009. The project is coordinated and funded by the ERS Educational Activities department. In April 2010, the Task Force drafted a list of topics mainly collected from educational material from courses organised by the ERS and other courses held in Antwerp and Edinburgh. The items on this list were reorganised to create a first draft of the "HERMES European Core Syllabus in Respiratory Disorders during sleep" in June 2010. This syllabus contained nine modules and 185 items focusing on the respiratory area of sleep disorders and aimed at targeting respiratory medicine specialists who would like to specialise in sleep respiratory

\section{Correspondence}

W. De Backer

Department of Pneumology

University Hospital Antwerp Wilrijkstr 10

2650

Edegem-Antwerp

Belgium

wilfried.debacker@ua.ac.be

\section{Competing interests}

A. Simonds has received research grants from ResMed for $£ 303,000$ and Breas Medical for $£ 45,000$. $S$. Andreas has received speaking fees from Heinen \& Löwenstein and Respironics. W. Randerath receives scientific grants, talk fees and travel grants from companies that are working in the field of sleep medicine (Weinmann, Respironics, Linde and ResMed). 


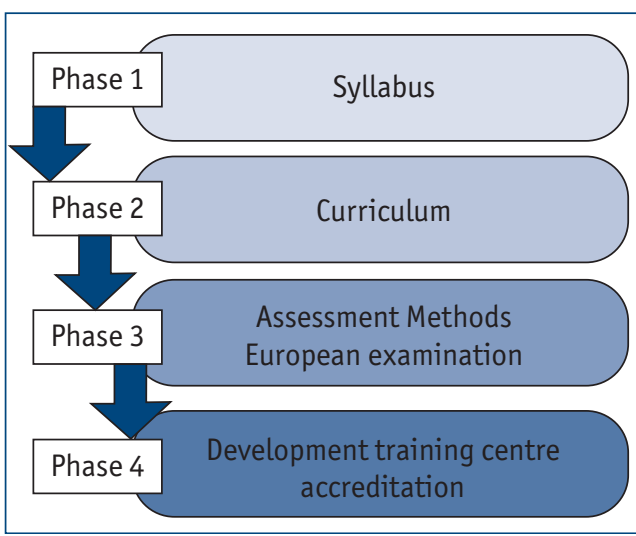

Figure 1

Four key phases of establishing consensus standards for training.

medicine. In this publication, we describe the process of the RSM syllabus development and present its final version.

\section{Methodology}

In line with the methodology previously used to produce the adult and paediatric HERMES syllabi, the Sleep Task Force decided to use a modified Delphi technique to develop the syllabus $[9,10]$. The Delphi technique has been shown to be a consensus development method of choice within the field of healthcare. It consists of an interactive process designed to lead to consensus within a panel of experts [11-13]. Several rounds of modified Delphi analysis using online surveys were performed to define a list of core skills and competencies any European practicing specialist in respiratory medicine should possess. The process involved three different groups. The Task Force consists of a Chair, two Cochairs, and 12 experts in the field and represents altogether seven different European countries (table 1). This group consists not only of representatives from the ERS but also the European Sleep Respiratory Society (ESRS) and the European Board for Accreditation in Pneumology (EBAP).

The Task Force identified the national respondents for the project through National Centres of Competence in Research across Europe. 21 national respondents participated to the syllabus development and contributed to the project, each representing one country (table 1).

The third group consists of members from the Clinical Physiology and Integrative Biology Assembly (Assembly 4), Sleep and Control of Breathing Group. Altogether, 285 respondents originating from 35 different countries were contacted during the syllabus development process (table 1). The majority of the respondents who actually participated in the surveys were either respiratory medicine specialists in clinical practice or sleep medicine specialists in clinical practice (fig. 2).

The syllabus development went through three rounds of surveys. The first survey was aimed at determining which sections and items should be included in the syllabus and whether they should be mandatory or optional. The results from the first survey were analysed during a face-toface meeting at the ERS Annual Congress in Barcelona, September 2010, to prepare a second draft of the syllabus. The revised syllabus was subjected to a second survey in order to decide which levels of competence for the syllabus items trainees should have acquired by the time they qualify as tertiary care specialists in RSM. Following the methodology used in the adult and paediatric HERMES projects [7], the levels of competence were defined as follows:

- Level 1/Basic: Awareness sufficient to recognise and know when to refer.

- Level 2/Intermediate: Knowledge sufficient to manage with consultation, under supervision or referral.

- Level 3/Advanced: Advanced knowledge sufficient for independent tertiary practice.

The results of the second survey were processed by the Task Force in December 2010 in Antwerp. Strong discrepancies were observed between the levels advised by the three groups of respondents and this led the Task Force members to conclude that in the context of RSM, the definitions of the levels of competence induce some confusion and needed to be revised as follows:

- Level 1/Basic: The item must be known by everybody involved in the respiratory sleep medicine field in daily practice.

- Level 2/Intermediate: Knowledge sufficient to manage with consultation, under supervision or referral.

- Level 3/Advanced: The topic need not be known by everyone in the RSM field. The item has the highest level of complexity and is highly specialised.

A proposed syllabus, including these levels of competence, was evaluated in a third online survey for which respondents were able to agree 
with the Task Force proposal or to suggest further levels of competence for the syllabus items. The revision of the definitions and the last round of the survey led to the finalised syllabus presented in this publication (Appendix 1).

\section{Results}

In order to address the general positioning of RSM in the different European countries, the surveys contained questions on the current professional position and country of origin of the respondents. About two-thirds of the respondents were either respiratory medicine specialists in clinical practice or sleep medicine specialists in clinical practice, and onethird were other specialists (fig. 2). Several different countries across Europe and worldwide were represented throughout the three rounds of the surveys (table 2).

The response rates were consistent in each survey round and varied between 19.4 and 31\%, across all groups of respondents.

The draft of the core syllabus in respiratory disorders during sleep contained nine sections and 185 items. The first survey was aimed at determining which sections should be included in the final syllabus and whether each item should be mandatory, optional or not included. In line with previous HERMES projects, it was initially proposed that the consensus would be reached when at least $80 \%$ of the respondents agreed on a question. Between 83.6 and 100\% of the respondents agreed on having all the sections included, indicating a consensus on the proposed sections of the syllabus. Nevertheless, altogether the respondents reached a consensus on only $45.4 \%$ of mandatory items. In particular, no agreement was reached on any of the 45 items of the paediatric module and the opinion of the respondents was divided between "mandatory" and "optional" choices. These results were debated at the ERS Annual Congress in Barcelona September 2011 by the Task Force with the perspective of redrafting the syllabus. It was decided that the threshold for consensus would be $70 \%$ agreement instead of $80 \%$ and to recommend having the paediatric module as mandatory for paediatricians and optional for any other specialists.

This revised document, reduced to eight modules and 172 items, was subjected to a second modified consensus-based survey to determine whether the paediatric module should be optional or mandatory and define the levels of competence of the syllabus. There

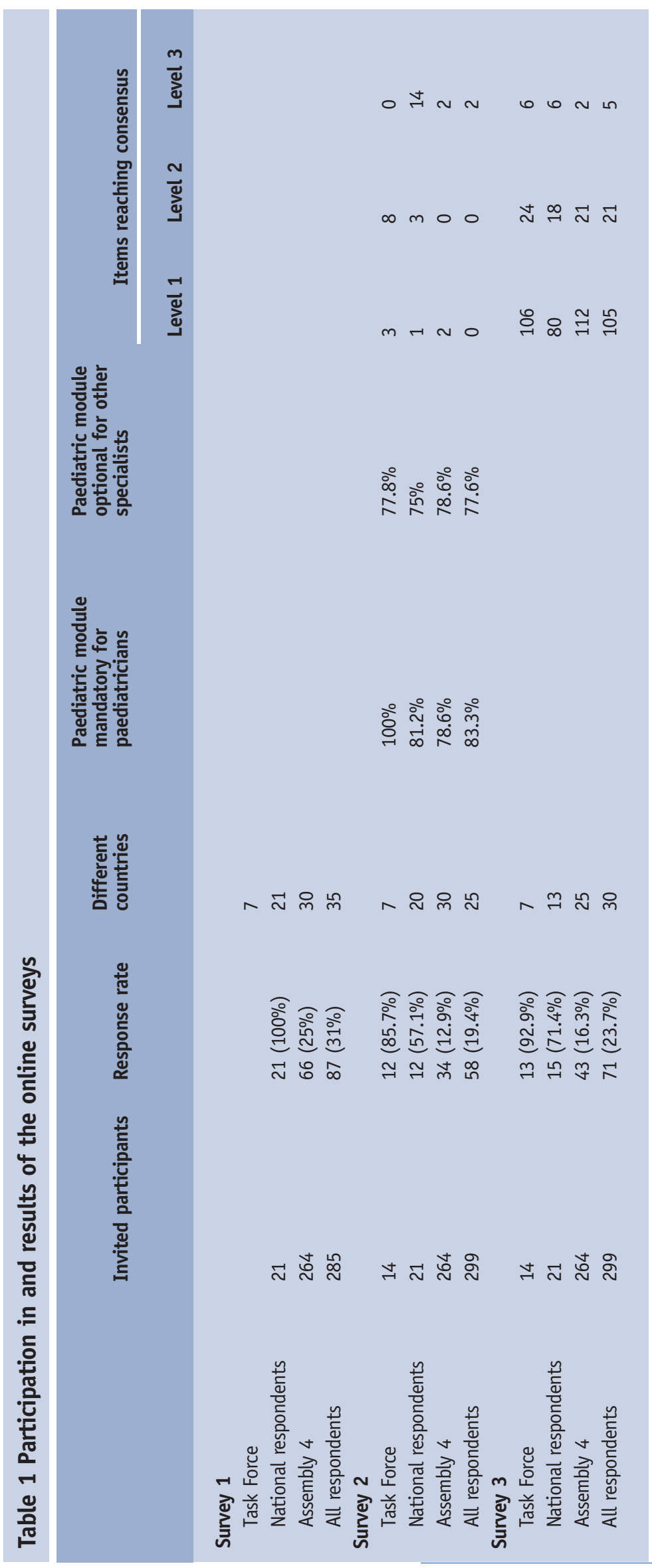




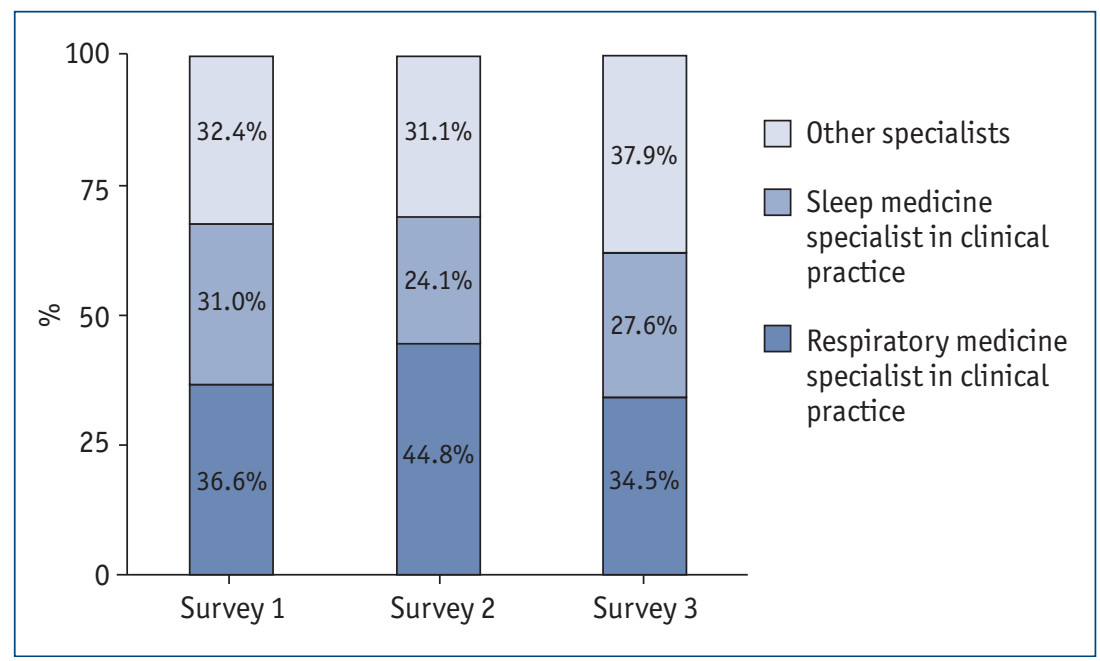

Figure 2

Breakdown of respondents to the surveys.

was consensus to include the paediatric module as a mandatory module for paediatricians and as an optional module for other specialists. Discrepancies in the results on the levels of competence across the three groups were dramatic: the Task Force recommended mainly the basic level, the national respondents the intermediate level and the Assembly 4 members primarily recommended the advanced level. The Task Force members revised the definitions for the sake of clarification and harmonisation between the three groups and produced a proposal for the syllabus, including these levels of competence.

The Task Force met in Prague to discuss the results of the last survey and update the syllabus.

\section{Table 2 Countries represented during all three rounds of the survey}

$\begin{array}{lll}\text { Romania } & \text { Poland } & \text { Denmark } \\ \text { UK } & \text { Portugal } & \text { Saudi Arabia } \\ \text { Greece } & \text { Sweden } & \text { Albania } \\ \text { Italy } & \text { Switzerland } & \text { Chile } \\ \text { Germany } & \text { Australia } & \text { Croatia } \\ \text { Belgium } & \text { Cyprus } & \text { Czech Republic } \\ \text { France } & \text { Egypt } & \text { Ecuador } \\ \text { Spain } & \text { Turkey } & \text { Japan } \\ \text { Ireland } & \text { Finland } & \text { Luxembourg } \\ \text { Slovak } & \text { Taiwan } & \text { Russia } \\ \text { Republic } & & \\ \text { Brazil } & \text { Iran } & \text { Serbia } \\ \text { Netherlands } & \text { Andorra } & \text { Slovenia } \\ \text { Austria } & \text { Bulgaria } & \\ \text { Lithuania } & \text { Canada } & \\ & & \end{array}$

Their proposal was almost unanimously accepted by respondents and they were able to proceed to finalise the HERMES European Core Syllabus in Respiratory Disorders during sleep (Appendix 1).

\section{Discussion}

Sleep respiratory medicine remains a relatively young specialty within the respiratory medicine field. It is a transversal specialty, practiced by sleep respiratory specialists as well as pneumologists and paediatricians. Diversity in training is significant throughout the different countries in Europe. Certain countries do not have any specific training at all and most of them do not possess a syllabus. This situation validated the requirement for such a project to produce first a syllabus, then a curriculum and finally an examination, with the ambition of establishing European Gold Standards in training, education and certification for this specialty. Such outcomes would not only facilitate the mobility of specialists across Europe but also improve patient care.

In contradiction to the adult and paediatric HERMES syllabi, all the sleep syllabus items are mandatory. This difference is somehow reflected in the recent development of RSM as a specialty and the lack of educational standards which could be applicable to countries within Europe. The development of the RSM syllabus allows two training possibilities, depending on the trainee specialty:

1. Any respiratory specialist who follows training with or without the paediatric module.

2. The second option includes a mandatory paediatric module for the paediatricians.

In both cases, this ensures that any specialist willing to be trained in paediatric RSM is expected to behave as a paediatrician.

\section{Conclusion}

In conclusion, the results of the different steps involved in the syllabus development revealed that the initiative of establishing educational standards in the field of respiratory disorders during sleep has been welcomed by respondents within Europe. This project emphasises a real need and expectation not only for a syllabus, but also for a well-defined and structured framework for education, including an examination, to promote the harmonisation of training and practice. 
Throughout the different phases of this project, the Task Force aims at offering a complete set of guidelines for the RSM specialisation, including training and certification. Within the foundations of this project, the syllabus identifies the knowledge, diseases and procedures required to become a specialist in the field. However, such a document makes sense only in a holistic context relying on the success of the next project phases: the curriculum and examination. The Task Force is currently developing the curriculum to describe how the knowledge and skills of the syllabus should be taught and learned, with a view to having the inaugural examination in 2013. As the curriculum is mainly intended for trainers, the Task Force decided to produce some educational materials to aid future trainees. Thus, the Task Force has begun work on a RSM Handbook, describing the content of the curriculum. With such a handbook, the project will have reached its aims by producing each element required to harmonise the training and certification of the RSM specialty.

\section{References}

1. Jennum P, Riha RL. Epidemiology of sleep apnoea/hypopnoea syndrome and sleep-disordered breathing. Eur Respir J 2009; 33: 907-914.

2. De Backer W. Sleep apnoea: what are the challenges for tomorrow? Breathe 2011; 7: 215-216.

3. De Backer W. Ostructive sleep apnoea/hypopnoea syndrome, In: Palange P, Simonds A, eds. ERS Handbook of Respiratory Medicine. 1st Edn. Sheffield, European Respiratory Society, 2010; pp. 404-409.

4. McNicholas W, Bonsignore M, eds. Sleep Apnoea. European Respiratory Monograph 50. Sheffield, European Respiratory Society, 2010.

5. Levy P, Pépin J-L, Tamisier R, et al. Prevalence and impact of central sleep apnea in heart failure. Sleep Med Clin 2007; 2: 615-621.

6. Al Lawati NM, Patel SR, Ayas NT. Epidemiology, risk factors, and consequences of obstructive sleep apnea and short sleep duration. Prog Cardiovasc Dis 2009; 51: 285-293.

7. Loddenkemper R, Séverin T, Mitchell T, et al. Adult HERMES: criteria for accreditation of ERS European training centres in adult respiratory medicine. Breathe 2010; 7: 170-176.

8. Cooper BG, Steenbruggen I, Mitchell S, et al. HERMES Spirometry: the European Spirometry Driving Licence. Breathe 2011; 7: 258-264.

9. Loddenkemper R, Séverin T, Eiselé J-L, et al. HERMES: a European Core Syllabus in Respiratory Medicine. Breathe 2006; 3: 59-69.

10. Gappa M, Noël J-L, Séverin T, et al. Paediatric HERMES: European Curriculum Recommendations for Training in Paediatric Respiratory Medicine. Breathe 2010; 7: 72-78.

11. Keeney S, Hasson F, McKenna HP. A critical review of the Delphi technique as a research methodology for nursing. Int J Nurs Stud 2001; 38: 195-200.

12. Goodman CM. The Delphi technique: a critique. J Adv Nurs 1987; 12: 729-734.

13. Ciałkowska M, Adamowski T, Piotrowski P, et al. [What is the Delphi method? Strengths and shortcomings.] Psychiatr Pol 2008; 42: 5-15.

\section{Appendix 1: Respiratory sleep medicine syllabus}

\section{MODULE 1 "Physiology and anatomy of sleep and breathing"}

1 Neuroanatomy and neurobiology of sleep

1.1 Regulation of the sleep-wake cycle including arousals

1.2 Sleep across lifespan

2 Breathing during sleep and wakefulness

2.1 Control of breathing during sleep and wakefulness

2.2 Anatomy and function of the upper airway

2.3 Respiratory mechanics and ventilation

3 Homeostatic regulation during sleep

3.1 Autonomic and cardiovascular regulations

3.2 Metabolic regulation

MODULE 2 "Respiratory conditions"

1 Definitions of sleep disordered breathing (OSA, OSAS, CSA, CSAS, CSR, OHS, UARS, Snoring)

2 Obstructive sleep apnoea (OSA)

2.1 Epidemiology of and risk factors for OSA

2.1.1 Obesity

2.1.2 Age

2.1.3 Sex

2.1.4 Other comorbidities
Level

1

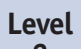

2

Level

3

.

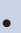

-

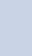

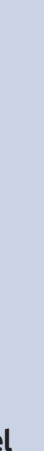




\subsection{Pathophysiology of OSA}

2.2.1 Craniofacial and upper airway morphology

2.2.2 Function and dysfunction of upper airway muscles

2.2.3 Central respiratory control mechanisms

2.3 Clinical aspects of OSA

2.3.1 Symptoms

2.3.2 Physical examination including upper airways

2.4 Consequences of OSA

2.4.1 Neurobehavioural (sleepiness, cognitive and psychiatric)

2.4.2 Cardiovascular

2.4.3 Metabolic

3 Central sleep apnoea (CSA) and Cheyne-Stokes respiration (CSR)

3.1 Epidemiology of and risk factors for CSA/CSR

3.1.1 Primary CSA

3.1.2 Secondary CSA

3.2 Pathophysiology of CSA/CSR

3.2.1 Primary CSA

3.2.2 Cardiovascular disorders

3.2.3 Opioid induced

3.2.4 High altitude

3.3 Clinical aspects of CSA

3.3.1 Symptoms

3.3.2 Physical examination

3.4 Consequences of CSA

3.4.1 Neurobehavioural (sleepiness, cognitive and psychiatric)

3.4.2 Cardiovascular

4 Hypoventilation syndromes

4.1 Central hypoventilation syndrome

4.2 Obesity hypoventilation syndrome

4.3 Neuromuscular disorders

5 Comorbid respiratory disorders

5.1 Asthma

5.2 Chronic obstructive pulmonary disease

5.3 Restrictive lung disorders

6 Comorbid nonrespiratory disorders

6.1 sleep in renal failure patients under dialysis (high rate of sleep problems)

\section{MODULE 3 "Nonrespiratory conditions"}

1 Classification

2 Insomnia

2.1 Primary insomnia

2.2 Secondary insomnia

3 Parasomnia and movement disorders during sleep

3.1 Periodic leg movement disorder and "restless legs" syndrome

3.2 REM-related disorders

3.3 Non-REM-related disorders

4 Hypersomnia

4.1 Narcolepsy

4.2 Idiopathic hypersomnia

5 Circadian rhythm disorders

5.1 Sleep-wake rhythm disorders

5.2 Shiftwork and sleep

6 Psychiatric aspects of sleep

MODULE 4 "Clinical assessment"

1 Sleep history 
2 Differential diagnosis of hypersomnolence, tiredness, sleepiness, fatigue

3 Application of diagnostic algorithms

4 Questionnaires on sleep

5 Quality of life

6 Assessment of surgical and anaesthesia risks

7 Predisposing factors

8 Comorbidity assessment

MODULE 5 "Diagnostic techniques"

1 Polysomnography

1.2 Sensors

1.3 Measurement techniques (including filters, calibration)

1.4 Scoring EEG according to R\&K and AASM

1.5 Scoring respiratory disturbances

1.6 Scoring movements during sleep

1.7 Evaluation of ECG

1.8 Interpretation of polysomnography

1.9 PTT

2 Assessment of daytime sleepness

2.1 MSLT

2.2 MWT

2.3 Non-EEG-based sleep tests

3 Cardiorespiratory monitoring during sleep

3.1 Polygraphy scoring: settings, trends and pitfalls

3.2 Interpretation of cardiorespiratory polygraphy

3.3 0ximetry

4 Actigraphy

5 (Nocturnal) capnography

MODULE 6 "Treatment and follow up"

1 Treatment of respiratory sleep disorders

1.1 Positive airway pressure (PAP) treatment

1.1.1 PAP principles and machines

1.1.2 PAP interfaces

1.1.3 PAP titration

1.2 OSA

1.2.1 Treatment algorithms

1.2.1.1 Patient education including life style modificaiton, sleep hygiene, PAP use

1.2.1.2 Positional treatment

1.2.1.3 PAP treatment (including CPAP, auto-CPAP and BPAP)

1.2.1.4 Oral devices/Mandibular repositioning splints

1.2.1.5 Surgery of the upper airway (including radiofrequency ablation technique)

1.2.1.6 Bariatric surgery

1.2.1.7 Drug treatment

1.2.1.8 Recognition and initial treatment of comorbidities

1.2.2 Follow-up and compliance

1.3 CSA

1.3.1 Treatment algorithms

1.3.1.1 Optimising treatment of underlying disorders

1.3.1.2 PAP treatment (including CPAP and BPAP)

1.3.1.3 Adaptive servo ventilation

1.3.1.4 0xygen therapy

1.3.1.5 Drug treatment

1.3.2 Follow-up and compliance

1.4 Hypoventilation/chronic respiratory insufficiency

1.4.1 Treatment algorithms 
1.4.1.1 Noninvasive ventilation

1.4.2 Follow-up and compliance

2 Treatment of nonrespiratory sleep disorders

2.1 Pharmacological

2.3 Non-pharmacological

MODULE 7 "Medicolegal aspects of sleep disorders"

1 Medicolegal aspects of sleep disorders

MODULE 8 "Paediatric"

1 Physiology

1.1 Ontogenesis and maturation of sleep in the first years of life

1.2 Ontogenesis and maturation of control of breathing in the first years of life

2 Respiratory conditions

2.1 Physiopathology, diagnosis and assessment of apnoea in infants/of ALTE

2.2 Physiopathology, epidemiology, diagnosis and assessment of sleep disordered breathing in children

2.2.1 Obstructive sleep apnoea

2.2.1.1 including risks, clinical aspects and consequences (neurocognitive mainly)

2.2.2 Sleep hypoventilation syndromes and central sleep apnoeas

2.2.2.1 including neuromuscular conditions and CCHS

2.2.3 Comorbid respiratory disorders

2.2.3.1 including allergic respiratory disorders and asthma, BPD and cystic fibrosis

3 Non respiratory conditions

3.1 Narcolepsy and other hypersomnias

3.2 ADHD and other behavioral disorders

3.3 Crossover between hypersomnias, behavioural disorders and SDB in children

4 Clinical assessment

4.1 Sleep history and clinical assessment of an infant

4.2 Sleep history and clinical assessment of a child

4.3 Indications for respiratory and nonrespiratory investigations

5 Diagnostic techniques

5.1 Polysomnography

5.1.1 Sensors

5.1.2 Scoring EEG in an infant/in a child

5.1.3 Scoring breathing in an infant/in a child

5.1.4 Normative data in an infant/in a child

5.1.5 Interpretation and report of polysomnography in an infant/in a child

5.2 Cardiorespiratory monitoring in children

5.2.1 Validity and reliability of polygraphy

5.2.2 Polygraphy scoring rules and report

5.3 0ximetry

5.4 Assessment of daytime sleepiness

5.4.1 MSLT and MWT: scoring rules, normative data

6 Management

6.1 Apnoeas in infants

6.2 OSA

6.2.1 Treatment options

6.2.1.1 Tonsillectomy and/or adenoidectomy and other ENT procedures

6.2.1.2 Craniofacial procedures

6.2.1.3 Orthodontic procedures

6.2.1.4 CPAP treatment

6.2.1.5 Lifestyle management

6.2.2 Indications

6.3 Sleep hypoventilation syndromes

6.3.1 Indications for noninvasive ventilation or tracheostomy ventilation 